\title{
Impact of Cost of Adverse Events After Kidney Transplantation
}

\author{
Bruna Cristina Cardoso Martins s,*, Kilvia Helane Cardoso Mesquita ${ }^{2}$, Iwyson Henrique Fernandes da Costa ${ }^{3}$, Elana Figueiredo Chaves ${ }^{4}$, \\ Paulo Yuri Milen Firmino ${ }^{5}$, Paula Frassinetti Castelo Branco Camurça Fernandes ${ }^{6}$, Marta Maria de França Fonteles ${ }^{1}$ \\ 'Pharmacy Department, Postgraduate Program in Pharmaceutical Sciences, Federal University of Ceará/Pastor Samuel Munguba Street, Fortaleza, Ceará, BRAZIL. \\ ${ }^{2}$ College of Economics, Federal University of Ceará, Universidade Avenue, Fortaleza, Ceará, BRAZIL. \\ ${ }^{3}$ Federal University of Minas Gerais Clinics Hospital, Professor Alfredo Balena Avenue, Belo Horizonte, Minas Gerais, BRAZIL. \\ 4Pharmacy Department, Federal University of Ceará, Capitão Francisco, Fortaleza, Ceará, BRAZIL. \\ ${ }^{5}$ Department of Pharmacy, Unifameter, Conselheiro Estelita Street, Fortaleza, Ceará, BRAZIL. \\ ${ }^{6}$ Renal Transplant Unit, Walter Cantídio University Hospital, Capitão Francisco Pedro Street, Fortaleza, Ceará, BRAZIL.
}

\begin{abstract}
Introduction: Kidney transplantation is considered the best treatment of rehabilitation for chronic kidney disease (CKD) patients, because it increases quality of life and survival when compared to other modalities of renal replacement. However, after kidney transplantation may occur clinical and surgical complications. Objectives: To evaluate the main causes of adverse events associated with renal graft and their impact on cost after kidney transplantation in the public system in Brazil. Methodology: Follow-up, descriptive, retrospective, exploratory, cause and effect study with economic evaluation. We used data from the Departamento de Informática do Sistema Único de Saúde (DATASUS). We identified patients with register of kidney transplant in the states of northern and northeastern Brazil in 2013 and had adverse event associated with renal graft. These patients were followed up through the registers on DATASUS, specifically using the Sistema de Informação Hospitalar SIH/SUS from 2013 to 2017. Results: A total of 183 patients with a renal graft-related adverse event during the first four years of kidney transplantation who required hospitalization for treatment. Patients up to six months after transplantation had a higher frequency of
\end{abstract}

readmissions and longer hospitalization. The impact of the cost of treating these patients on the total cost of readmissions was US\$302,952.05. Conclusion: Through the data analysis from SIH/SUS, it was possible to identify that the complications related to renal graft had significant impact of cost on the value of readmissions after kidney transplantation.

Key words: Adverse Events, Graft Rejection, Health Care Costs, Health Expenditures, Kidney Transplantation.

\section{Correspondence}

Prof. Bruna Cristina Cardoso Martins

Pharmacy Department, Postgraduate Program in Pharmaceutical Sciences, Federal University of Ceará/ Pastor Samuel Munguba Street, number-1210, Fortaleza, Ceará, BRAZIL.

Phone: +558533668058

Email: bbrunacristina@hotmail.com

DOI: 10.5530/jyp.2020.12.13

\section{INTRODUCTION}

Kidney transplantation is considered the best treatment of rehabilitation for chronic kidney disease (CKD) patients, because it increases quality of life and survival when compared to other modalities of renal replacement. $^{1,2}$

The Sistema Único de Saúde (SUS) in Brazil provides universal and free coverage, including high complexity procedures, in which organ transplantation is granted. ${ }^{3}$ Thus, SUS is responsible for all the transplant costs, since the search for potential donors, transplant procedure and follow-up after the surgery. ${ }^{4}$ In Brazil, according to data of the Brazilian Association of Organ Transplantation (BAOT), 5,923 kidney transplants were done in $2018 .^{5}$

Despite the significant advances, clinical and surgical complications after the surgery still represent important causes of morbidity and mortality. The most common complications are early graft dysfunction, rejections, infections caused by microorganisms, dyslipidemia, diabetes, hypertension and bone problems. ${ }^{6-8}$

In Brazil, initial expenditures with renal transplant are high, due to the surgical procedure, but the ones regarding the follow-up are low. In addition, transplant has shown to be the therapeutic alternative with lower cost than hemodialysis and peritoneal dialysis. ${ }^{9}$ However, it is necessary the assessment of the after transplant complications, because the costs with adverse events correspond to a significant part of direct hospital costs, what represents a high impact in the budget of hospital admis- sions. ${ }^{10}$ Treatment of these events in the kidney transplant patient, most of the times, requires hospitalization. ${ }^{11}$

In Brazil, the Ministry of Health provides a Sistema de Informação Hospitalar (SIH/SUS), which stores data regarding the hospital internment provided by SUS, monthly reported by all the contracted public healthcare institutions that offer hospital admissions. The data are consolidated by municipalities and states that send to DATASUS after their analysis and approval. The database is fed after filling out the Autorização de Internação Hospitalar (AIH). ${ }^{12}$

It is possible, through the data available on SIH/SUS, to evidence the cost and characteristics of the complications after kidney transplant in the different Brazilian regions and in different periods of time. Conducting a research about the complications after kidney transplant, assessing the cost in two different Brazilian regions, has important relevance for an efficient management of the resources and a better monitoring of patients. This study aimed to analyze the main causes of adverse events associated with renal graft and the impact of cost after kidney transplantation in the public system in Brazil.

\section{MATERIALS AND METHODS}

This is follow-up, descriptive, retrospective, exploratory, cause and effect study with economic evaluation in which the universe were patients with register of kidney transplant in 2013 in the Northern and Northeastern 
Brazil. We assessed the adverse events related to the kidney graft during the four first years of transplant of these patients. Databases from different years and Brazilian states were associated through data linkage. We used the SIH/SUS as database, from the Information Department of SUS. The submission to the Human Research Ethics Committee was not required, as the research used publicly available information under law No. 12.527 / 2011 and without the possibility of individual identification, as provided for in Resolution No. 510/2016. ${ }^{13,14}$ The sample consisted of readmissions between 2013 and 2017. The inclusion criteria were patients who had register of kidney transplant in the year of 2013 according to SIH/SUS in the Northern and Northeastern Brazil; whereas the exclusion criteria were patients with complications not related to kidney transplant.

\section{Analysed Variables}

We analyzed the following variables in the study: sex; age, race/color, rate of adverse events associated with renal graft in the four first years after kidney transplant; International Classification of Diseases (ICD10) and average of length of hospital stay for treatment of adverse event. Data were collected by a researcher from June to December 2018 on the DATASUS website (http://www2.datasus.gov.br/DATASUS/index. php?area $=0901$ \&item $=1 \&$ acao $=25)\left(\right.$ BRASIL, 2017) ${ }^{15}$

\section{Economic Evaluation}

This is a partial cost analysis, cost-consequence type, in which we analyzed the costs related to readmissions due to complications after kidney transplant. We only analyzed direct costs, in the Brazilian currency (US\$) and in the perspective of SUS. The real Brazilian currency was converted to the American dollar using the 2017 value for the last followup year. Data were also analyzed separately in the Northern and Northeastern regions of Brazil.

\section{Statistical Analysis}

The files were extracted from the SIH / SUS base in .dbc format and expanded in the TabWin program to .dbf. Through the program convince to be exporting to $\mathrm{Excel}^{\circledR}$ version 2016. Statistical analysis was performed using the SPSS program. A crossover was performed between variables in which the causes and consequences were determined. In the analysis of numerical variables, the variance analysis test (three groups) were applied $(\mathrm{p}<0,05)$. All statistical analyses were performed using Statistical Package for the Social Sciences (SPSS) 21.0.0.0. Data were presented as graphs and tables.

\section{RESULTS}

A total of 183 patients with kidney transplant register in 2013, which had adverse events related to the graft during the first four years after transplant, were included in the study. These patients correspond to $20,5 \%$ $(n=183 / 893)$ of those transplanted in 2013. The mean age of patients, during the occurrence of the adverse event, was 44 years old ( \pm 13 years) and $67.7 \%(n=124)$ were male (Table 1$)$. The total number of readmissions was 403 and each patient, in average, was readmitted twice for treatment of adverse event related to the graft.

The readmissions happened with higher frequency ( $n=240 ; 59.7 \%)$ during the first six months of post kidney transplant. Besides that, the admissions in the period from 6 months until 2 years occurred in $25.4 \%$ $(n=103)$ of the times and they decreased when patients had more than two years of kidney transplant $(n=60 ; 14.9 \%)$.

ICD with higher frequency of readmissions was End-stage renal disease (N18.0) with 35.98\% ( $n=145$ ) (Figure 1). During the follow-up period, we have found 9 death registers, in which $77.8 \%(n=7)$ were in the first six months of kidney transplant and $22.2 \%(n=2)$ were in the period from 6 months to 2 years.

Main ICDs registered as cause of death were: Respiratory arrest (R09.2; $n=5 ; 55.6 \%)$, Acute Respiratory Failure (J96.0; $n=1 ; 11.1 \%)$, End-stage renal disease $(\mathrm{N} 18.0 ; n=1 ; 11.1 \%)$, Kidney Transplant Failure and Rejection $(\mathrm{T} 86.1 ; n=1 ; 11.1 \%)$ and Acute Kidney Failure, unspecified (N17.9; $n=1 ; 11.1 \%)$.

Regarding the length of stay of the admission, we analyzed that: $52.6 \%$ $(n=212)$ of the readmissions length less than 10 days, $43.4 \%(n=175)$ length among 10 and 30 days and $4 \%(n=16)$ a prolonged time longer than 30 days.

The average of the daily rate for treatment of the patient's clinical condition was US\$ 52.06 , with a total spend of all readmissions of US\$ $302,952.05$ in which $84.7 \%$ (US\$ $256,445.72$ ) were hospital spends and $15.3 \%$ (US\$ 46,506.33) spends with human resources. The diagnosis with higher spend was End-stage kidney disease $(n=145)$ with an amount of US\$ $132,904.36$ (25.2\%) for 145 readmissions (Table 2). The average of length of stay with diagnosis N18.0 was 9 days (min: 1 day and max: 33 days).

The period after transplant in which the adverse event occurred $(\leq 6$ months) and the length of the stay (among 10 and 30 days) for treatment had statistically significant correlation with total cost of the readmission (Table 3).

Regarding the kind of admission, $80.6 \%(n=325)$ were urgency and $17.4 \%(n=70)$ were elective, that is, most patients had graft complications that needed immediate assistance. $41.23 \%(n=134)$ of the urgent care assistances were related to ICD N18.0, while $61.43 \%(n=43)$ of the elective had as main diagnosis ICD N18.8. The average daily cost was very similar: urgency was US\$ 53.59 and the elective US\$ 46.6. Besides that, $88.89 \%(n=8)$ of patients who died were in urgent care assistance.

The impact of the cost of the treatment of these patients in relation to total cost of readmissions (US\$528,329.50) was of 57.3\% (US\$302,952.05).

\section{DISCUSSION}

The analyses of health situations, in Brazil, can be carried out with aid of Health Information Systems of the Brazilian Ministry of Health. ${ }^{16,17}$ Thus, by filling the Authorization for Hospital Admission (AIH) which is monthly sent by the municipal and/o state manager to DATASUS, it is possible to have individualized data by non-identified patient about admission, diagnose, procedures and costs. ${ }^{18}$

The occurrence of adverse events related to the renal graft was frequent in the period until 6 months after the kidney transplant, patients in this

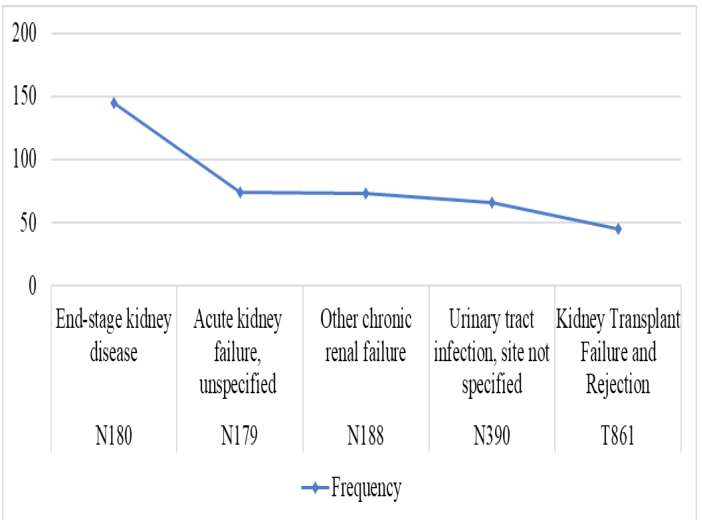

Figure 1: Main diagnoses registered in the admissions during post kidney transplant ( $n=403)$. Brazil, 2019. (Statement: at column width). 
Table 1: Epidemiological profile of patients followed up from 2013 to $\mathbf{2 0 1 7}$ for assessment of adverse events after kidney transplant ( $\boldsymbol{n}=$ 183). Brazil, 2019. (Statement: at column width).

\begin{tabular}{|c|c|c|c|}
\hline \multicolumn{2}{|c|}{ Variables } & \multirow{2}{*}{$\frac{\mathrm{N}}{124}$} & \multirow{2}{*}{$\begin{array}{c}\% \\
67.7\end{array}$} \\
\hline Sex & Male & & \\
\hline \multirow[t]{4}{*}{ Race/color } & Brown & 96 & 52.4 \\
\hline & No Information & 63 & 34.4 \\
\hline & White & 14 & 7.6 \\
\hline & Black & 10 & 5.6 \\
\hline \multirow[t]{3}{*}{ Age } & Max. & \multicolumn{2}{|c|}{79 years old } \\
\hline & Min. & \multicolumn{2}{|c|}{5 years old } \\
\hline & Mean \pm SD & \multicolumn{2}{|c|}{44 years old \pm 13} \\
\hline \multirow[t]{3}{*}{ Readmissions } & Max. & \multicolumn{2}{|c|}{25} \\
\hline & Min. & \multicolumn{2}{|c|}{1} \\
\hline & Mean & \multicolumn{2}{|c|}{2} \\
\hline
\end{tabular}

Table 2: Description of registered ICD as adverse event of kidney graft, frequency and cost ( $n=403)$. Brazil, 2019. (Statement: at column width).

\begin{tabular}{lccc}
\hline & Main Diagnosis - ICD & N & Cost (US\$) \\
\hline N18.0 & End-stage kidney disease & 145 & $132,904.36$ \\
N17.9 & Acute kidney failure, unspecified & 74 & $61,040.16$ \\
N18.8 & Other chronic renal failure & 73 & $40,177.34$ \\
N39.0 & Urinary tract infection, site not specified & 66 & $40,238.30$ \\
T86.1 & Kidney Transplant Failure and Rejection & 45 & $28,882.82$ \\
& & 403 & $302,952.05$ \\
\hline \multirow{2}{*}{ TOTAL } & & & \\
\end{tabular}

time range stayed longer at the hospital, as well as in the study conducted in Iran by Lankarani, Noorbala and Assari (2009). ${ }^{13}$

Just as found in another study conducted in Canada, age and male sex were not determinative for a higher frequency of adverse events. ${ }^{19}$ In a study conducted by Grupta et al. (2019) the mean age was $35.61 \pm$ $10.64 .{ }^{19,20}$ Besides that, the predominance of the male sex agrees with other studies, which point a higher prevalence of renal failure in men than in women. ${ }^{20,21}$ In the assessment conducted by Carlotto and colleagues (2019) in Brazil, patients with complications also were male, although with mean age of $36.3 \pm 7.4$. There is proximity of identified ages in the literature and the present study, reinforcing the profile of patients submitted to kidney transplant. ${ }^{22}$

Even with the transplant for treating the renal failure, the higher frequency of graft dysfunction was due to end-stage kidney disease. The development of a system that predicts the risk of renal graft loss is a reality due to the frequency of this event. ${ }^{23}$ Associated to these factors, there is the occurrence of unspecified acute renal failure in the hospital readmission of the patients. ${ }^{24}$

Besides that, the incidence of infections also increased the readmissions of patients in the period up four years after transplant. During the initial period, patients use high doses of immunosuppressant drugs for preventing graft rejection, thus the pharmacotherapy of these patients includes antibiotics, antiparasitic and antiviral drugs as prophylaxis treatment for opportunistic infections. ${ }^{25}$ In the study of Ruppel and colleagues (2018), it was shown that infection was the main cause of mortality in the first five years after kidney transplant. ${ }^{26}$

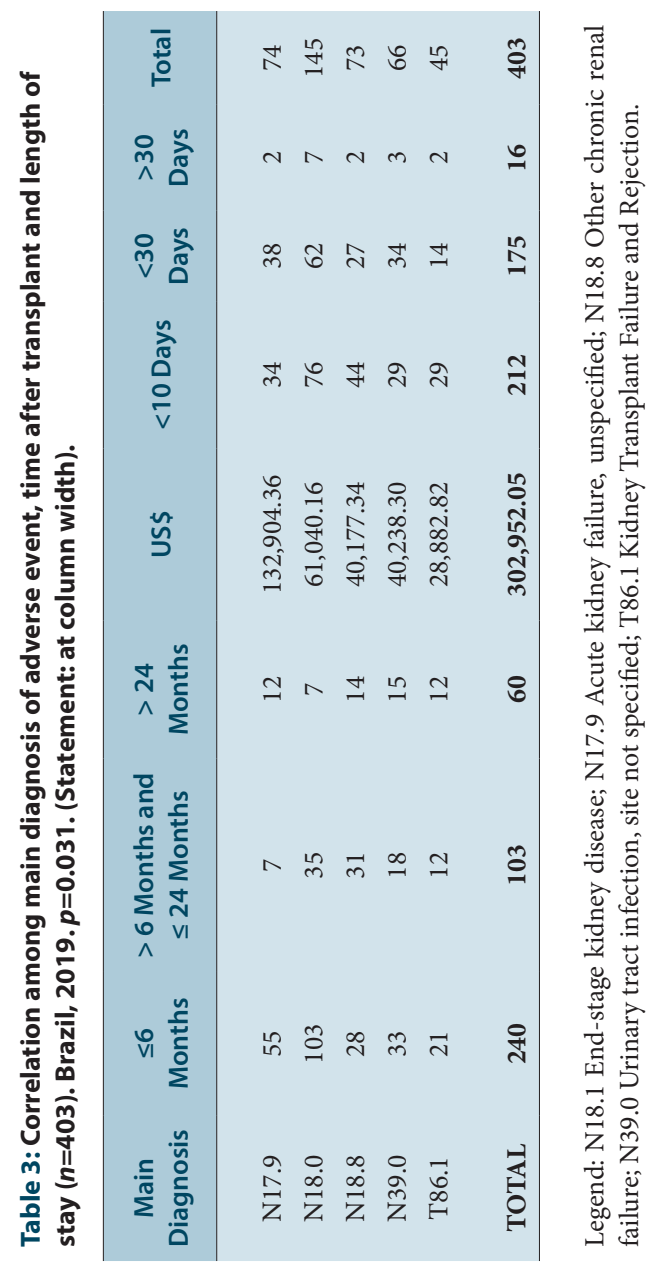

The type of initial care to the patient may be decisive to the prognosis, in the cases, which involved adverse events regarding the renal graft, in this study, the great part of patients had graft complications that needed immediate care and deaths had occurred in these circumstances. However, there was not a higher cost when compared to elective care. Although the direct costs of patients who died were lower, there is a huge impact in the indirect costs such as the intangible costs for the society.

The treatment of patients with adverse events related to the renal graft had a significant cost impact in relation to the total cost spent in this period for hospital treatment of patients who underwent kidney transplant. The occurrence of readmissions after transplant and, in this case, consequent to adverse events increased the value of the transplant and in another study, it is possible to evidence this association..$^{22,27}$

However, it can be evidenced that costs with adverse events decreased in the period of two years after the transplant, because there was a reduction in the readmissions and length of hospital stay. In the analysis lead by Zur-Mühlen et al. (2018), the costs with transplant dropped after one year and stayed stable until four years. ${ }^{28}$

Besides the costs generated with readmissions of post-transplant patients for treatment of adverse events, kidney transplant has shown the lower cost among the therapies for renal failure. Because the initial spend with transplant is elevated due to the surgical procedure, as well as the spends with maintenance in the normal course of follow up are reduced, however, dialysis therapy have its costs elevated with time, justified by the progressive loss of the organ. ${ }^{29,30}$ 


\section{CONCLUSION}

By tracking the occurrence of adverse events, with aid of a Health Information System of the Brazilian Ministry of Health, it was possible to evidence the great impact of costs involved in the readmission of patients for treatment of adverse events related to the renal graft in the first four years. It was possible to identify that patients up to six months after transplant had higher frequency of readmissions and longer length of stay, thus, subsidize changes and specifications in the protocols of treatment after transplant, which could minimize this incidence.

\section{ACKNOWLEDGEMENT}

Federal University of Ceará and Ministry of Health of Brazil.

\section{CONFLICT OF INTEREST}

The authors declare none.

\section{ABBREVIATIONS}

CKD: Chronic Kidney Disease; DATASUS: Departamento De Informática Do Sistema Único De Saúde; SIH/SUS: Sistema De Informação Hospitalar; SUS: Sistema Único De Saúde; BAOT: Brazilian Association Organ Transplantation; AIH: Autorização De Internação Hospitalar; ICD-10: International Classification of Disease.

\section{REFERENCES}

1. Penteado AP, Cohrs FM, Hummel AD, Erbs J, Maciel RF, Ortolani CLF, et al. Kidney Transplantation Process in Brazil Represented in Business Process Modeling Notation. Transplant Proc. 2015;47(4):963-6.

2. Branchereau JK. Management of Urologic Complications of Renal Transplantation. Eur Urol Suppl. 2016;9(15):408-14.

3. Medina-Pestana JO, Galante NZ, JrTedesco-Silva H, Harada KM, Garcia VD, Abbud-Filho M, et al. Kidney transplantation in Brazil and its geographic disparity. J Bras Nefrol. 2011;33(4):472-84.

4. Costa CKF, Neto GB, Sampaio LMB. Eficiência dos estados Brasileiros e do distrito federal no sistema público de transplante renal: Uma análise usando método DEA (Análise Envoltória de Dados) e índice de Malmquist. Cad Saude Publica. 2014;30(8):1667-79.

5. Registro Brasileiro de Transplantes (RBT). Ano XXIV, $n^{\circ} 4$. Dimensionamento dos Transplantes no Brasil e em cada Estado (2011-2018). 2018. Available from: <http://www.abto.org.br/abtov03/Upload/file/RBT/2018/Lv_RBT-2018.pdf>

6. Rahnemai-Azar AA, Gilchrist BF, Kayle LK. Independent risk factors for early urologic complications after kidney transplantation. Clin Transplant. 2015;5(29):4038

7. Haberal M, Boyvat F, Akdur A, Kırnap M, Özçelik Ü, Karakayalı FY. Surgical complications after kidney transplantation. Exp Clin Transplant. 2016;14(6):587-95.

8. Nygaard RM, Sirany AM, Wyman EA, Bodner J, Richardson CJ, Ney AL, et al. A clinical tool to risk stratify potential kidney transplant recipients and predict severe adverse events. Clin Transplant. 2016;11(30):1494-500.

9. Silva SB, Caulliraux HM, Araújo CAS, Rocha E. Uma comparação dos custos do transplante renal em relação às diálises no Brasil. Cad Saude Publica. 2016;32(6):e00013515.

10. Carey K, Stefos T. Controlling for quality in the hospital cost function. Health Care Manag Sci. 2011;14(2):125-34.

11. Lankarani MM, Noorbala MH, Assari S. Causes of re-hospitalization in different post kidney transplantation periods. Ann Transplant. 2009;14(4):14-9.
12. Ministério da Saúde [homepage na Internet]. SIHSUS - Sistema de Informações Hospitalares do SUS. Available from: <http://datasus.saude.gov.br/sistemas-e-aplicativos/hospitalares/sihsus>.

13. Brasil. Lei $n^{\circ} 12.527$, de 18 de novembro de 2011. Lei de Acesso à Informação. 2011. Available from: http://auriflama.sp.gov.br/files/decreto_7724_16.pdf.

14. Brasil. Resolução $n^{\circ}$ 510, de 07 de abril de 2016, Conselho Nacional de Saúde. 2016. Available from: http://www.gppege.org.br/ArquivosUpload/1/file/ Res_\%20CNS\%20510-2016\%20\%C3\%89tica\%20na\%20Pesquisa.pdf

15. Brasil. Ministério da Saúde. SIH - Sistema de Informação Hospitalar do SUS: Manual Técnico Operacional do Sistema. Brasília. 2017. Available from: < http:// www.saude.sp.gov.br/resources/ses/perfil/gestor/homepage/auditoria/manuais/manual_sih_janeiro_2017.pdf>

16. Szuster DAC, Silva GM, Andrade ELG, Acúrcio FDA, Caiaffa WT, Gomes IC, et al. Potencialidades do uso de bancos de dados para informação em saúde: o caso das Terapias Renais Substitutivas (TRS) - morbidade e mortalidade dos pacientes em TRS. Rev méd Minas Gerais. 2009;19(4):308-16. Available from:<http:// www.medicina.ufmg.br/rmmg/index.php/rmmg/article/download/190/175>

17. Szuster DAC, CaiaffaWT, Andrade EIG, DeAcurcio FA, Cherchiglia ML. Sobrevida de pacientes em diálise no SUS no Brasil. Cad Saude Publica. 2012;28(3):41524.

18. Silva JPL, Travassos C, Vasconcellos MM, Campos LM. Systematic review on usage of large databases data linkage in research in public health in Brazil. Cad Saúde Colet. 2006;14(2):197-224.

19. ElRaichani L, Du Q, Mathieu A, Almassy S, Lalonde L, Berbiche D, et al. Development and validation of PART (Pharmacotherapy Assessment in Renal Transplant Patients) criteria to assess drug-related problems in an outpatient renal transplant population: A cross-sectional study. Pharmacol Res Perspect. $2019 ; 7(1): 1-10$

20. Gupta KL, Pattanashetti N, Ramachandran R, Nada R, Aggarwal R, Sharma A. Renal transplant and its outcomes: Single-center experience from India. Exp Clin Transplant. 2019;17(Suppl 1):78-82.

21. Martins BCC. Pharmacotherapeutic follow-up of renal transplant patients: from description to clinical outcomes. Dissertation (Master in Pharmaceutical Sciences). Faculty of Pharmacy, Dentistry and Nursing, Federal University of Ceará, Fortaleza, Brazil. 2015

22. Carlotto JRM, Linhares MM, Netto AAS, Range ÉB, Medina-Pestana JO, Ferraro JR, et al. Simultaneous pancreas-kidney transplantation and the impact of postoperative complications on hospitalization cost. Rev Col Bras Cir. 2019;46(1):e2096.

23. Loupy A, Aubert O, Orandi BJ, Naesens M, Bouatou Y, Raynaud M, et al. Prediction system for risk of allograft loss in patients receiving kidney transplants: international derivation and validation study. BMJ. 2019;366:|4923.

24. Arms MA, Fleming J, Sangani DB, Nadig SN, McGillicuddy JW, Taber DJ. Incidence and impact of adverse drug events contributing to hospital readmissions in kidney transplant recipients. Surgery. 2018;163(2):430-5.

25. Gnatta D, Keitel E, Heineck I, Garcia VD. Guia Prático para Atividade de Farmácia Clínica: Transplante Renal. Brasil: EDUCS. 2019;56.

26. Ruppel P, Felipe CR, Medina-Pestana JO, Hiramoto LL, Viana L, Ferreira A, et al. The influence of clinical, environmental and socioeconomic factors on five-yea patient survival after kidney transplantation. J Bras Nefrol. 2018;40(2):151-61.

27. Li B, Cairns J, Fotheringham J, Ravanan R. Predicting hospital costs for patients receiving renal replacement therapy to inform an economic evaluation. Eur $\mathrm{J}$ Heal Econ. 2016;17(6):659-68

28. Zur-Mühlen B, Wintzell V, Levine A, Rosenlund M, Kilany S, Nordling S, et al. Healthcare Resource Use, Cost and Sick Leave Following Kidney Transplantation in Sweden: A Population-Based, 5-Year, Retrospective Study of Outcomes: COIN. Ann Transplant. 2018;23:852-66.

29. Cherchiglia ML, Gomes IC, Alvares J, Júnior AG, DeAcúrcio FA, Andrade EIG, et al. Determinantes dos gastos com diálises no Sistema Único de Saúde, Brasil, 2000 a 2004. Cad Saude Publica. 2010;26(8):1627-41.

30. Eriksson JK, Neovius M, Jacobson SH, Elinder CG, Hylander B. Healthcare costs in chronic kidney disease and renal replacement therapy: A populationbased cohort study in Sweden. BMJ Open. 2016;6(10):e012062.

Article History: Submission Date :04-11-2019 ; Revised Date : 01-12-2019 ; Acceptance Date : 10-12-2019

Cite this article: Martins BCC, Mesquita KHC, Costa IHF, Chaves EF, Firmino PYM, Fernandes PFCBC, Fonteles MMF. Impact of Cost of Adverse Events After Kidney Transplantation. J Young Pharm. 2020;12(1):67-70. 